NASA TECHNICAL MEMORANDUM

(NASA-TH-X-71525) CATALYTIC TRIMERIZATION OF AROHATIC NITRILES FOR SYNTHESIS OF POLYIUIDE MATRIX RESINS (NASA) 14 pHC
NASA TM X- 71525

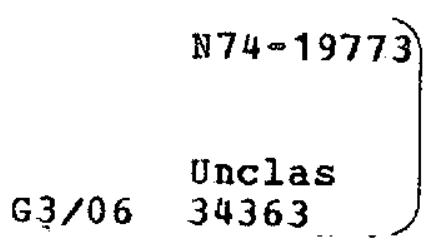

G3/06 34363

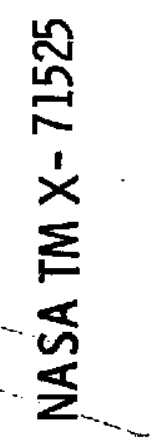

CSCL $07 D$

CATALYTIC TRIMERIZATION OF AROMATIC NITRILES

FOR SYNTHESIS OF POLYIMIDE MATRIX RESINS

by Li-Chen Hsu

Lewis Research Center

Cleveland, Ohio 44135

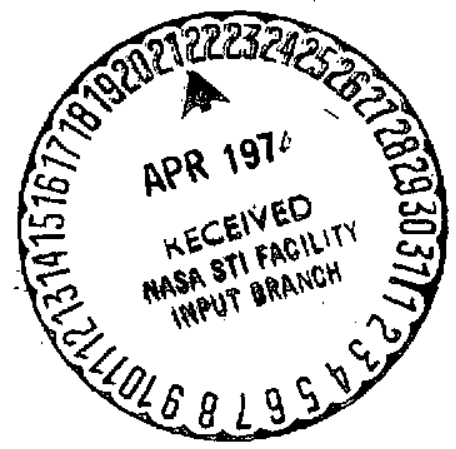

TECHNICAL PAPER proposed for presentation at

Symposium on New Industrial Polymers, Division of Organic

Coatings and Plastics Chemistry, 167th Spring National

Meeting of the American Chemical Society

Los Angeles, California, April 2, 1974 


\title{
CATALYTIC TRIMERIZATION OF AROMATIC NITRILES \\ FOR SYNTHESIS OF POLYIMIDE MATRIX RESINS
}

\author{
by Li-Chen Hsu
}

Lewis Research Center

\section{SYNOPSIS}

Aromatic nitriles may be trimerized at moderate temperature and pressure with p-toluenesulfonic acid as catalyst. Studies were conducted to establish the effect of the reaction temperature, pressure, time, and catalyst concentration on yield of the trimerized product. Trimerization studies were also conducted to establish the effect of substituting electron donating or withdrawing groups on benzonitrile. Preliminary results of using the catalytic trimerization approach to prepare s-triazine cross-linked polyimide/graphite fiber composites are presented.

\section{INTRODUCTION}

High temperature resin/fiber composites have the potential of meeting the performance requirements for many advanced aerospace structures. The composites need to exhibit retention of mechanical properties during continuous use at $316^{\circ} \mathrm{C}\left(600^{\circ} \mathrm{F}\right)$ or above (1). Among the high temperature resins, polyimides occupy a preeminent position. Aromatic polyimides ( $\mathrm{Pr}$ 's) exhibit thermal stability in excess of $500^{\circ} \mathrm{C}\left(932^{\circ} \mathrm{F}\right)$ as determined by thermal gravimetric analysis. (2). However processing difficulties have limited their use as matrices in resin/fiber composites. Various approaches have been used to solve the processability problem of polyimides. Lubowitz (3) and Burns et. al. (4) developed a new system of processable addition-type (A-type) PI's by end-capping imide oligomers with norbornenyl groups. After removal of the solvent, the norbornene-terminated imide oligomers are polymerized through the double bonds without evolution of byproducts. Serafini et. al. (5) and Delvigs et. al. (6) developed an improved processing technique for A-type PI's called the in situ polymerization of monomeric reactants (PMR). 
Although the in situ PMR approach does provide void free A-type PI composites with good property retention at $316^{\circ} \mathrm{C}\left(600^{\circ} \mathrm{F}\right)$, the alicyclic ring structure derived from the norbornene groups does appear to limit the thermo-oxidative stability (TOS) of A-type PI's (7). To achieve A-type PIs with improved TOS at $316^{\circ} \mathrm{C}\left(600^{\circ} \mathrm{F}\right)$ or above, our approach was to replace the norbornenyl groups with aromatic nitriles. Trimerization of aromatic nitrile-terminated imide oligomers should lead to new polyimides containing triaryl-s-triazine rings. Triaryl-s-triazine ring is known to exhibit good thermal stability (8).

The purpose of the present investigation was to study the trimerization of aromatic nitriles under the conventional resin/fiber composite fabrication conditions using p-toluenesulfonic acid as a catalyst. Trimerization pararneters investigated included reaction temperature, pressure, time, and concentration of catalyst. The influence of the nature of aromatic nitriles on trimerization was also studied. Also presented are preliminary results on the use of the catalytic trimerization of the nitrile-terminated imide oligomers to fabricate graphite fiber reinforced composites.

\section{EXPERIMENTAL PROCEDURE}

\section{Materials}

All of the aromatic nitriles except p-cyanophthalanil used in this study were purchased from commercial sources and used as received. The p-cyanophthalanil was synthesized by a method similar to that used for synthesizing N-phthalyl-L- $\beta$-phenylalanine (9) except that $p$-aminobensonitrile was used instead of $\mathrm{L}$-phenylalanine.

\section{Catalytic Trimerization}

About 0.01 mole of the aromatic nitrile together with 0.5 to 5.0 mole percent of the p-toluenesulfonic acid (PTSA) catalyst was introduced into a 45-milliliter stainless steel pressure vessel. The vessel was flushed with nitrogen gas and the initial pressure in the vessel was varied from 0 to 2.76 $\mathrm{MN} / \mathrm{m}^{2}$ ( 0 to $400 \mathrm{psi}$ ). The vessel was then heated to temperatures in the range of 100 to $316^{\circ} \mathrm{C}$. The selected temperature was maintained for 24 to 90 hours. The PTSA catalyst and unreacted nitrile were then removed from 
the product by washing with water followed by distillation under reduced pressure. The product was then recrystallized from xylene or glacial acetic acid. Melting point and infrared spectrum were determined for identification purposes.

\section{RESULTS AND DISCUSSION}

\section{Trimerization Study}

Bengelsdorf (10) reported that aromatic nitriles could be trimerized in the absence of catalysts at temperatures in the range of $350^{\circ}$ to $500^{\circ} \mathrm{C}$ and at pressures which ranged from $3.55 \times 10^{3}$ to $5.06 \times 10^{3} \mathrm{MN} / \mathrm{m}^{2}(35,000$ to 50,000 atmospheres). Cairns et al. (11) used various alcohols as catalysts and were able to effect trimerization of aromatic nitriles at $60^{\circ}$ to $150^{\circ} \mathrm{C}$ and $0.3 \times 10^{3} \mathrm{MN} / \mathrm{m}^{2}$ (above 3000 atmospheres). Kunz et al. (12) employed chlorosulfonic acid to trimerize aromatic nitriles at temperatures in the range of $-10^{\circ}$ to $30^{\circ} \mathrm{C}$ and at atmospheric pressure. These latter workers used an excess of chlorosulfonic acid which apparently served as both the solvent and catalyst. Because of the high pressures or the nature and quantity of catalyst employed none of the methods described above are suitable for the synthesis of high temperature resistant s-triazine cross-linked polyimide matrix resins for fiber reinforced composites.

The aromatic nitrile and catalyst selected for this study were benzonitrile and PTSA, respectively. Studies were conducted to establish the effect of reaction conditions on yield of trimerized product. Figure 1 shows the effect of varying the reaction temperature on yield between $100^{\circ}$ and $290^{\circ} \mathrm{C}$ at a constant PTSA catalyst concentration of 5 mole percent, pressure in the range of 4.14 to $5.17 \mathrm{MN} / \mathrm{m}^{2}$ (600 to $\left.750 \mathrm{psi}\right)$, and for a constant reaction time of 66 hours. It can be seen from the figure that there 
was no yield at $100^{\circ} \mathrm{C}$ and the yield nearly doubled on going from $232^{\circ}$ to $290^{\circ} \mathrm{C}$. Because of practical processing considerations for the fabrication of fiber reinforced composites, higher temperatures were not investigated. The effect of reaction pressures in the range of 0.2 to $5.17 \mathrm{MN} / \mathrm{m}^{2}$ (30 to $750 \mathrm{psi}$ ) on yield are shown in figure 2. The data shown in this figure were obtained for reactions conducted with a PTSA concentration of 5 mole percent at $232^{\circ} \mathrm{C}$ for 66 hours. The figure shows that the use of higher pressures resulted in higher yields. Hereto, practical processing consideration limited the highest pressure studied to $5.17 \mathrm{MN} / \mathrm{m}^{2}$ (750 psi). Figure 3 shows the effect of reaction time on yield for reactions conducted with 5 mole percent PTSA at $232^{\circ} \mathrm{C}\left(450^{\circ} \mathrm{F}\right)$ and $5.17 \mathrm{MN} / \mathrm{m}^{2}(750 \mathrm{psi})$. It can be seen in the figure that the yield upon increasing reaction time from 24 to 66 hours underwent slightly more than a two fold increase. Figure 4 which shows effect of catalyst concentration on yield shows that at $232^{\circ} \mathrm{C}\left(450^{\circ} \mathrm{F}\right)$ and $5.17 \mathrm{MN} / \mathrm{m}^{2}(750 \mathrm{psi})$ and 66 hours the yield increased from $5 \%$ to $17 \%$ for a ten fold increase in catalyst concentration.

The results of these trimerization parameter studies indicated that useful levels of trimerized product (cross-links) could be anticipated from the use of this catalytic trimerization approach in fabricating resin/fiber composites. Two additional points need to be made with respect to the yield of trimerized product. First, the yield of trimerized product (cross-links) in an actual resin/fiber composite might be increased by post-curing at elevated temperatures. And secondly, extensive cross-linking may not be necessary for improved composite properties and indeed may be deleterious to certain composite mechanical properties.

\section{Nature of Aromatic Nitriles}

The experimental results on the influence of ring substituents on the ease of trimerizing benzonitriles are summarized in Table I. It can be seen that the benzonitriles bearing electron withdrawing ring substituents such as carboxyl and nitro groups are more susceptible to trimerization than those bearing electron donating substituents such as methyl and methoxy groups. The lower yield of trimerized product from the o-nitrobenzonitrile compared to p-nitrobenzonitrile can be accounted for by steric effects. The very high yield of trimerized product from the $\mathrm{p}$-cyanobenzoic acid might 
have resulted from a reaction in which the p-cyanobenzoic acid itself served as a co-catalyst.

For the synthesis of processable polyimides, our results suggested the use of 4-cyanophthalic anhydride as the end-capping reagent. The 4-cyanophthalic anhydride or its esters might be preferrable because the electron withdrawing carbonyl groups would be directly attached to the aromatic ring containing the nitrile to be trimerized. However, because of the commercial availability of $\mathrm{p}$-aminobenzonitrile, it was selected as the end-capping reagent for preliminary studies.

\section{Trimerization of p-Cyanophthalanil}

p-Cyanophthalanil was synthesized as the model compound to study the effectiveness of PTSA in promoting trimerization of a chemical structure which would be found in the polyimide precursors.

p-Cyanophthalanil was prepared from commercially available p-aminobenzonitrile and phthalic anhydride. The white crystalline powder has a melting point of $189^{\circ} \mathrm{C}$ (lit. $187^{\circ} \mathrm{C}$, ref. 16). Its infrared spectrum showed a nitrile band at $2240 \mathrm{~cm}^{-1}$, imide bands at $1795,1755,1735$, and $1380 \mathrm{~cm}^{-1}$, and phenyl ring bands at 1610 and $1520 \mathrm{~cm}^{-1}$ respectively (fig. 5 (a)).

Catalytic trimerization of p-cyanophthalanil with 5 mole percent p-toluenesulfonic acid at $250-300^{\circ} \mathrm{C}$ and 4.97 to $5.52 \mathrm{MN} / \mathrm{m}^{2}(720-800 \mathrm{psi})$ for 90 hours gave a $97 \%$ yield product, with a m.p. $>340^{\circ} \mathrm{C}$. The infrared spectrum showed the disappearance of the nitrile band at $2240 \mathrm{~cm}^{-1}$ and the broadening of the s-triazine bands at 1520 and $1380 \mathrm{~cm}^{-1}$ (fig. 5(b)). Further identification of the formation of the s-triazine was done by refluxing the trimerized product with a $10 \%$. NaOH solution for 4 hours. The infrared spectrum. of the insoluable hydrolysis product showed that those imide bands at 1795 , 1755,1735 , and $1380 \mathrm{~cm}^{-1}$ had nearly disappeared (or greatly weakened). The characteristic s-triazine band at $1520 \mathrm{~cm}^{-1}$ was not effected (fig. $5(\mathrm{c})$ ). 


\section{Trimerization of Terephthalonitrile}

Since terephthalonitrile has two nitrile groups and the nitrile group itself is also electron withdrawing, catalytic trimerization of terephthalonitrile should proceed readily and result in a polymeric product expected to exhibit good thermal stability. The experimental results confirmed this prediction: Catalytic trimerization of terephthalonitrile with 5 mole percent of PTSA catalyst at $232^{\circ} \mathrm{C}$ and $5.17 \mathrm{MN} / \mathrm{m}^{2}$ (750 psi) for 48 hours gave a product $\left(99.5 \%\right.$ yield) with a melting point $>340^{\circ}\left(644^{\circ} \mathrm{F}\right)$. The infrared spectrum of terephthalonitrile showed a very strong nitrile band at $2230 \mathrm{~cm}^{-1}$ and a sharp aromatic ring band at $1500 \mathrm{~cm}^{-1}$ (fig. 6(a)). The infrared spectrum of the trimerized product showed strong and broad characteristic s-triazine ring bands at 1525 and $1370 \mathrm{~cm}^{-1}$ with a residual nitrile band of medium strength at $2230 \mathrm{~cm}^{-1}$ (fig. 6(b)). Thermal gravimetric analysis (fig. 7) showed that the weight losses of terephthalonitrile polymer were about $7 \%$ after heating to $316^{\circ} \mathrm{C}\left(600^{\circ} \mathrm{F}\right)$ and $18 \%$ after heating to $538^{\circ} \mathrm{C}\left(1000^{\circ} \mathrm{F}\right)$ respectively. Anderson and Holovka (17) reported weight losses of about $25 \%$ after heating to $316^{\circ}\left(600^{\circ} \mathrm{F}\right)$ and $75 \%$ after heating to $538^{\circ} \mathrm{C}\left(1000^{\circ} \mathrm{F}\right)$ respectively from the terephthalonitrile polymer which they obtained by treating terephthalontrile with chlorosulfonic acid at $0^{\circ} \mathrm{C}$. This greater thermal oxidative stability of the trimerized product using PTSA as the catalyst may be due to having achieved a higher cross-link density during reaction at $232^{\circ} \mathrm{C}\left(450^{\circ} \mathrm{F}\right)$ and $5.17 \mathrm{MN} / \mathrm{m}^{2}(750 \mathrm{psi})$.

Polyimide/Graphite Fiber Reinforced Composite

Since aromatic nitrile-terminated imide oligomers are similar in nature as p-cyanophthalanil and possess the same functionality as terephthalonitrile, they should be able to trimerize and form the s-triazine ring containing polymers under the similar reaction conditions.

Preliminary work for the synthesis of nitrile terminated polyimides was carried out by using $p$-aminobenzonitrile, 4, 4' -methylenedianiline, $3,3^{\mathrm{r}}$, $4,4^{\prime}$-benzophenonetetracarboxylic dianhydride and methanol with 2.5 mole percent of PTSA catalyst. The stoichiometry of the monomeric reactants was adjusted to yield an in situ prepolymer having an average formulated 
molecular weight of 1500 . Composite fabrication and testing were performed essentially according to the method used in reference 5 . The results from some preliminary composite fabrication and characterization studies indicate that the trimerization technique by employing PTSA catalyst provides high performance composites.

Table II shows the interlaminar shear strength and flexural strength of the triaryl-s-triazine cross-linked PI/HMS graphite composites at room temperature and $316^{\circ} \mathrm{C}$ with and without post curing. The data clearly indicate that the HMS graphite fiber reinforced composite prepared from a nitrite terminated PI exhibited very good retention of flexural strength during short time exposure in air at $316^{\circ} \mathrm{C}$. More inportant, the data also indicate that both the interlaminar shear strength and flexural strength of the composites improved after a 16 hour post cure at $316^{\circ} \mathrm{C}$. Apparently this resulted from an increase in triaryl-s-triazine rings during post cure at $316^{\circ} \mathrm{C}$.

\section{CONCLUSIONS}

The results of this investigation lead to the following conclusions:

1. Aromatic nitriles can be trimerized in the temperature range of $200^{\circ}$ to $316^{\circ} \mathrm{C}\left(392^{\circ}\right.$ to $\left.600^{\circ} \mathrm{F}\right)$ and pressure range of 1.38 to 5.52 $\mathrm{MN} / \mathrm{m}^{2}$ (200 to $800 \mathrm{psi}$ ) with p-toluenesulfonic acid as catalyst.

2. Benzonitriles bearing electron withdrawing ring substituents were found more susceptible to trimerization than those bearing electron donating ring substituents.

3. Polyimide matrix resins containing s-triazine cross-links can be easily prepared using the aromatic nitrile end-capping approach and trimerization with a p-toluenesulfonic acid catalyst. 


\section{REFERENCES}

1. T. T. Serafini in "Aerospace Structural Materials," National Aeronautics Space Administration Special Publication No. 227, Washington, D.C., 1970, p. 207.

2. C. E. Sroog, J. Polymer Sci., C, 16, 1191 (1967).

3. H. R. Lubowitz, E. R. Wilson, W. P. Kendrick, and E. A. Burns,

French Patent 1, 572, 798 (1969); H. R. Lubowitz, U.S. Patent 3, 528, 950 (1970); Chem. Abstr., 72, 56085k (1970).

4. E. A. Burns, R.J. Jones, R.W. Vaughan, and W. P. Kendrick, "Thermally Stable Laminating Resins, ${ }^{\text {" }}$ Report TRW-11926-6013-R0-00; NASA CR-72633, TRW System Group, Redondo Beach, Calif., 1970.

5. T. T. Serafini, P. Delvigs, and G. R. Lightsey, "Thermally Stable Polyimides from Solutions of Monomeric Reactants, " Report TN-D-6611, National Aeronautics and Space Administration, Washington, D.C., 1972; J. Appl. Polymer Sci., 16, 905 (1972).

6. P. Delvigs, T.T. Serafini, G.R. Lightsey, "Addition-Type Polyimides from Solutions of Monomeric Reactants, " Report TN-D-6877, National Aeronautics and Space Administration, Washingyon, D.C., 1972; Materials Review for '72: Proceedings of the National Symposium and Exhibition, Science of Advanced Materials and Process Engineering Series, Vol. 17, 1972, p. III-B-7-1.

7. R.J. Jones, R.W. Vaughn, and E. A. Burns, "Thermally Stable Laminating Resins, "Report TRW-16402-6012-R0-00; NASA CR-72984, TRW System Group, Redondo Beach, Calif., 1972.

8. E.S. Blake, W.C. Hammann, J.W. Edwards, T.E. Reichard, and M. R. Ort, J. Chem. Eng. Data, 16, 87, (1961).

9. A.K. Bose, "Organic Synthesis," Collect. Vol. 5, Wiley, New York, N. Y., 1973, p. 973.

10. I.S. Bengelsdorf, J. Amer. Chem. Soc., 80, 1442 (1958).

11. T. L.S. Cairns, A.W. Larchar, and B.C. McKusick, U.S. Patent 2,503, 999 (1950); Chem. Abstr., 44-, 6445c (1950). 
12. M. A. Kunz, K. Koeferle, and E. Berthold, U.S. Patent 1,989, 042 (1935); Chem. Abstr. , 29, 1834 (1935).

13. E. M. Smolin and L. Rapoport, "s-Triazines and Derivatives," Interscience, New York, 1967, p. 172.

14. 14. J.E. Mahan and S.D. Turk, U.S. Patent 2, 598, 811 (1952); Chem. Abstr., 46, $10212 \mathrm{~h}$ (1952).

15. G. Martins Filho, J. Goncalves da Costa, F. Soares de Azevedo, and J.O. Falcao de Morais, Anais. Acad. Brasil, Cienc., 35, 185 (1963).

16. M. T. Bogert and L. E. Wise, J. Amer. Chem. Soc., 34, 693 (1912).

17. D. R. Anderson and J. M. Holovka, J. Polymer Sci., A-1, 4, 1689 (1966). 


\section{TABLE I. - CATALYTIC TRIMERIZATION* OF SUBSTITUTED BENZONITRILES}

Aromatic Nitrile M.P. ${ }^{\circ} \mathrm{C} \quad$ Trimerized Product Percent yield M.P. ${ }^{\circ} \mathrm{C}$ (Value in Lit.)

$\begin{array}{lccc}\text { p-Tolunitrile } & 26-28 & 5.0 & >340\left(278-9^{13}\right) \\ \text { Anisonitrile } & 55-56 & 6.0 & >340\left(217 \text { and } 224^{13}\right) \\ \text { Benzonitrile } & -14 & 14.0 & 232-235\left(232^{13}\right) \\ \text { o-Nitrobenzonitrile } & 102-106 & 37.8 & >340^{14} \\ \text { p-Nitrobenzonitrile } & 146-149 & 52.3 & >340\left(>360^{13}\right) \\ \text { p-Cyanobenzoic acid } & 220-222 & 75.0 & >340\left(374-5^{15}\right)\end{array}$

* Reaction conducted at $232^{\circ} \mathrm{C}$, and 600 to $750 \mathrm{psi}$., with 5 mole percent of PTSA catalyst for 48 hours. 
TABLE II. - MECHANICAL PROPERTIES OF TRIARYL-S-TRIAZINE CROSS-LINKED PI/HMS FIBER COMPOSITES ${ }^{a}$

\begin{tabular}{|c|c|c|c|c|c|c|}
\hline \multirow{3}{*}{$\begin{array}{l}\text { Speci- } \\
\text { men }\end{array}$} & \multicolumn{3}{|c|}{ Interlaminar shear strength, psi } & \multicolumn{3}{|c|}{ Flexural strength, psi } \\
\hline & \multirow{2}{*}{$\begin{array}{l}\text { Room } \\
\text { temper- } \\
\text { ature }\end{array}$} & \multicolumn{2}{|r|}{$600^{\circ} \mathrm{F}$} & \multirow{2}{*}{$\begin{array}{l}\text { Room } \\
\text { temper- } \\
\text { ature }\end{array}$} & \multicolumn{2}{|r|}{$600^{\circ} \mathrm{F}$} \\
\hline & & $\begin{array}{l}\text { No post } \\
\text { cure }\end{array}$ & $\begin{array}{c}\text { Post cure } \\
\left(16 \mathrm{hr} 600^{\circ} \mathrm{F}\right)\end{array}$ & & $\begin{array}{l}\text { No post } \\
\text { cure }\end{array}$ & $\begin{array}{c}\text { Post cure } \\
\left(16 \mathrm{hr} 600^{\circ} \mathrm{F}\right)\end{array}$ \\
\hline 1 & 8370 & 4620 & 7500 & 155000 & 148200 & 167500 \\
\hline 2 & 10130 & 4520 & 6800 & 130200 & 145700 & 157500 \\
\hline
\end{tabular}

${ }^{\mathrm{a}} \mathrm{Resin} /$ fiber $\sim 40 / 60$ by weight. 


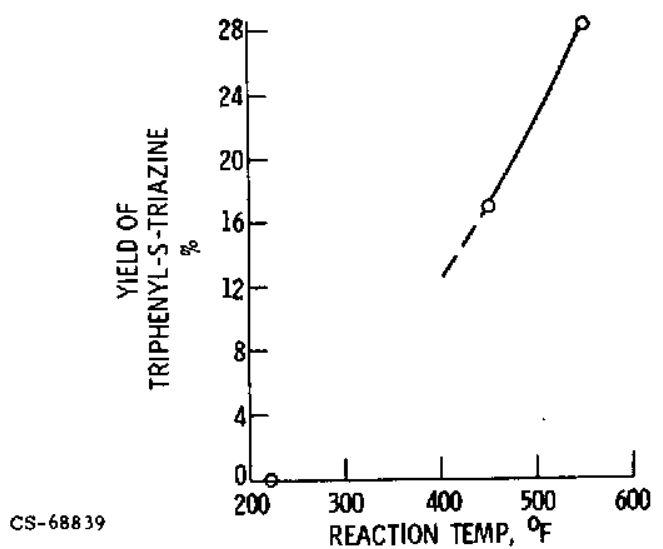

Figure 1. - Effect of reaction temperature on trimerization of benzonitrile (PTSA 5 moles $\%, 600-750$ psi, $66 \mathrm{hr}$.)

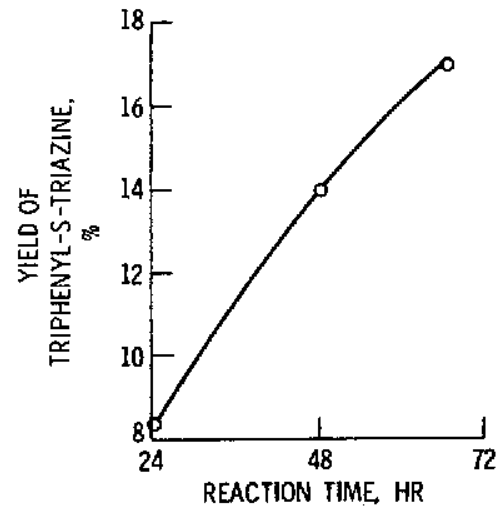

Figure 3. - Effect of reaction time on trimerization of benzonitrile (PTSA 5 mole \%. $450^{\circ} \mathrm{F}, 750 \mathrm{psil}$.

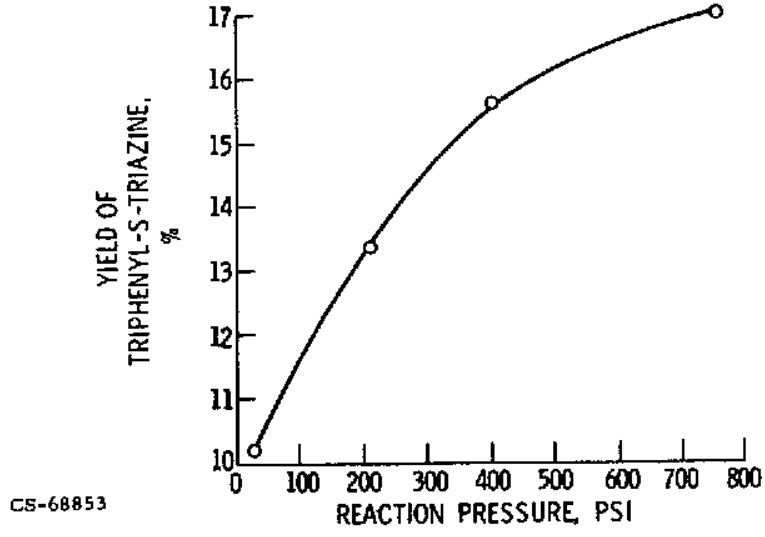

Figure 2 - Effect of reation pressure on trimerization of benzonitrile (PTSA 5 mole \%, $450^{\circ} \mathrm{F}, 66 \mathrm{hr}$.)

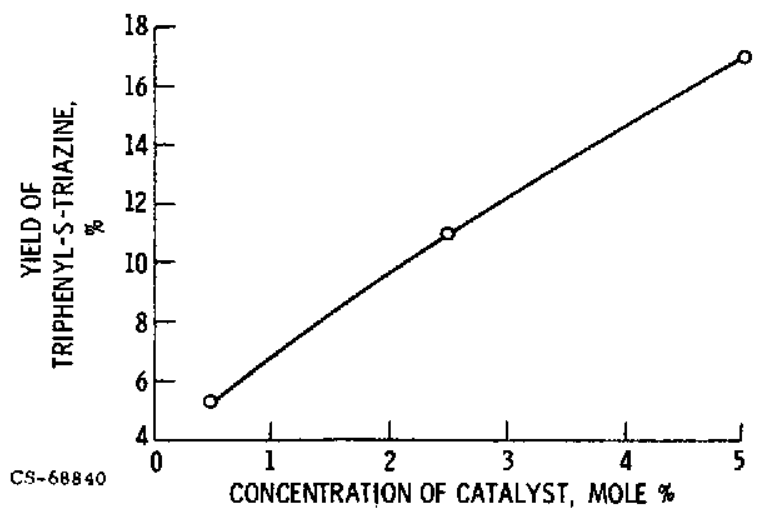

Figure 4. - Effect of catalyst concentration on trimerization of benzonitrile (PTSA, $450^{\circ} \mathrm{F}, 750 \mathrm{psi}, 66 \mathrm{hr}$ ). 


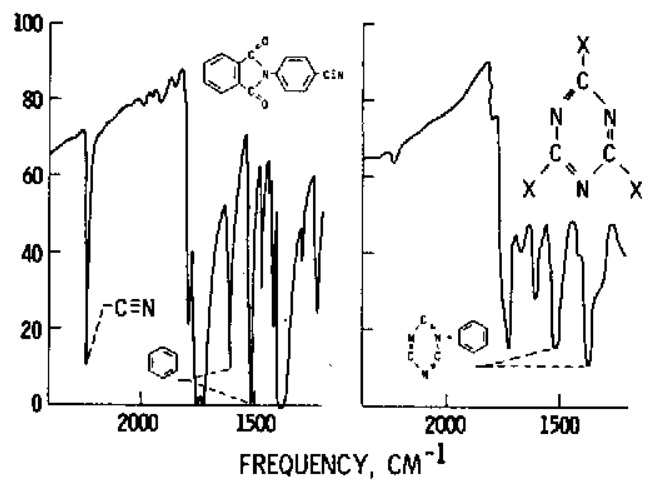

$\begin{array}{ll}\text { (a) IR SPECTRUM OF } P- & \text { (b) IR SPECTRUM OF }\end{array}$ CYANOPHTHALANIL TRIMERIZED PROD (PCPLAL). TRIMERIZED PROD
UCT OF PCPLAL

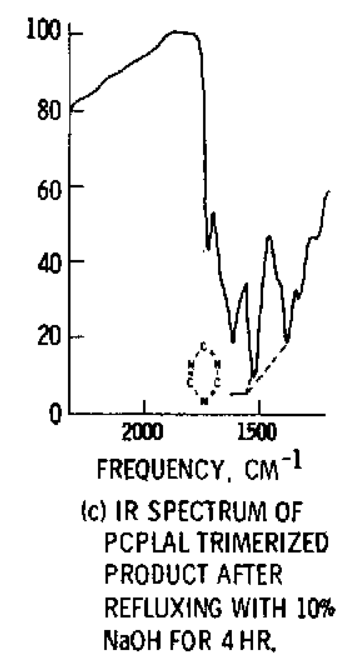

Figure 5.

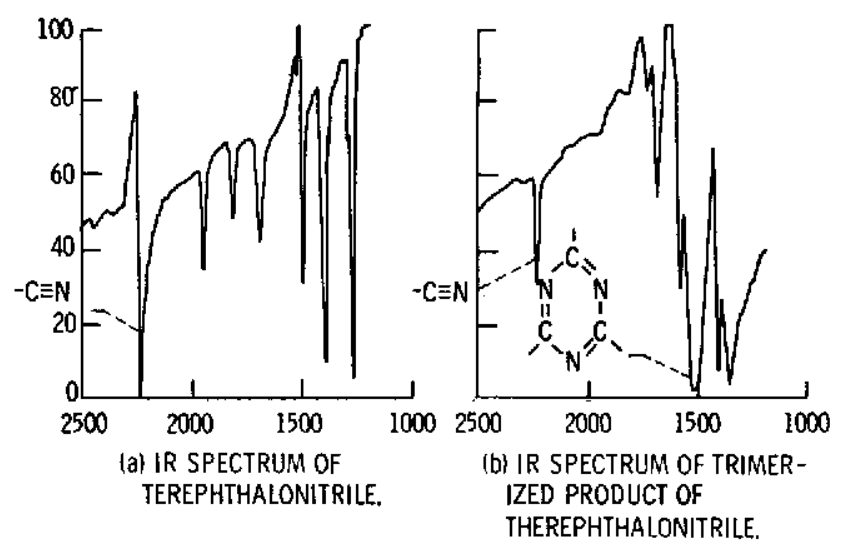

Figure 6.

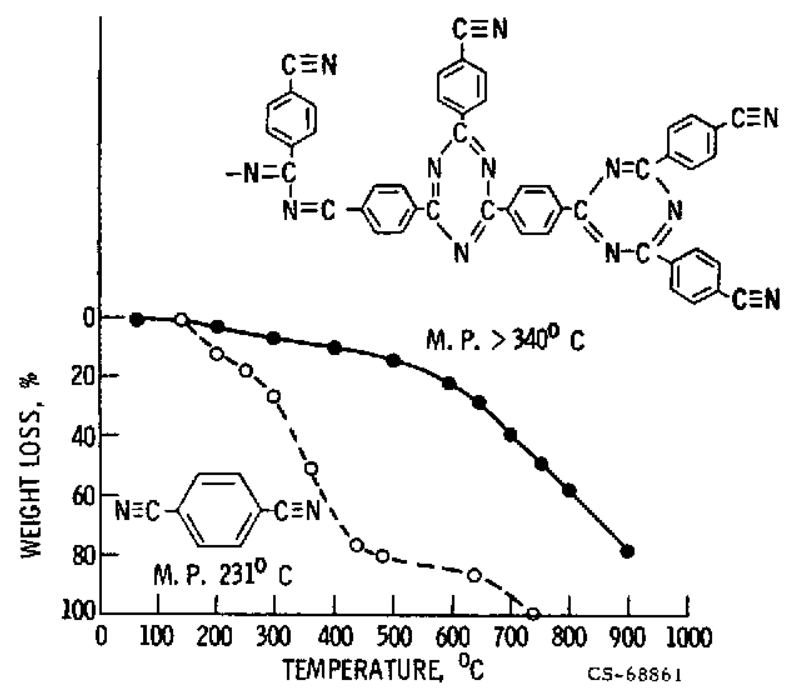

Figure 7. - TGA thermograms $\left(10^{\circ} \mathrm{C} / \mathrm{min}, \mathrm{N}_{2}\right)$ of terephthalonitrile (O) and its trimerized product $(\bullet)$. 